\title{
La iglesia de las Santas Justa y Rufina en Orihuela. Evidencias constructivas para la posible intervención de este Bien de Interés Cultural
}

\author{
Silvia Spairani Berrio, Yolanda Spairani Berrio, Miguel Louis Cereceda, \\ Luis Jaime Morales Gisbert \\ Universidad de Alicante
}

\begin{abstract}
En este artículo se efectúa un análisis histórico, arquitectónico y constructivo de la Iglesia de las Santas Justa y Rufina, en Orihuela, así como una exposición del estado actual del monumento para aportar directrices que garanticen una intervención coherente y respetuosa con un Bien de Interés Cultural, en el que conviven un crisol de arquitecturas góticas, renacentistas y barrocas. Además, planteamos evidencias para la reflexión sobre las principales hipótesis respecto a la bóveda central de adscripción cronológica incierta. Tras analizar la historia de la construcción de la iglesia y de sus sistemas constructivos detectamos numerosas adversidades y transformaciones en el tiempo y el espacio, llegándose a declarar la iglesia incluso en ruina, a principios del siglo XX. Las grietas vivas actuales denotan movimientos generados, entre otras causas, por la subsidencia del terreno que afecta a la ciudad.
\end{abstract}

\section{PALABRAS CLAVE:}

Arquitectura histórica; iglesia gótica; técnica constructiva; estudio-diagnóstico; Bien de interés cultural.

\section{ABSTRACT:}

This article is effected an historical, architectural and constructive analysis of the church of the Saints Justa and Rufina in Orihuela, as well as an exhibition in the current context of the monument for provide guidelines to ensure the coherent and respectful intervention with a Culture Heritage Site, within which architectures Gothic, Renaissance and Baroque architectures coexist. In addition, we raised evidence for reflection on the major assumptions that secondment center dome in chronological uncertain. After analysis of the history of the construction of the church and his constructive systems we detected that the church has undergone numerous adversities and transformations in the time and space, coming to declare the church even in ruin at the beginning of the 20th century; the current live cracks denote generated movements, among other reasons, by the subsidence of the land affecting the city.

\section{KEYWORDS:}

Historic Architecture; gothic church; constructive techniques; diagnostic study, culture heritage site. 


\section{Introducción}

La Iglesia de las Santas Justa y Rufina posee un gran patrimonio cultural, arquitectónico y arqueológico en relación a la forma, el espacio, la tecnología constructiva y las relaciones estratigráficas y tipológicas de sus materiales. El edificio está catalogado como Monumento Nacional, siendo la fecha de declaración, de 1 de abril de 1971, con Código: (R.I)-51-000385900000. La Iglesia actual es conforme a lo establecido en el Real Decreto 111/1986, de 10 de enero, de desarrollo parcial de la Ley 16/1985, de 25 de junio, de Patrimonio Histórico Español y se le aplica, a día de hoy, la consideración de Bien de Interés Cultural (BIC).

Desde el punto de vista arquitectónico, decidimos plantear dos fases para un correcto desarrollo del estudio diagnóstico constructivo de esta iglesia: la caracterización constructiva de su arquitectura y el estudio de sus lesiones, o de su estado actual. En la $1^{\text {a }}$ fase, procedemos a la observación y toma de datos de la iglesia, aspectos que nos permiten, por una parte, identificar la realidad constructiva del edificio a través del dibujo de su arquitectura, caracterizada por la confirmación del tipo de lesión y la definición de su grafiado y, por otra, estudiar las pautas de la evolución de los procesos de alteración sufridos y su importancia. En la $2^{\text {a }}$ fase y una vez identificadas las lesiones, estudiamos las causas que las producen y evaluamos su funcionalidad, para servir de base sustentadora a posibles intervenciones a acometer en el BIC.

D. Pedro Sáez $(1998)^{1}$ y Da ${ }^{a}$ Begoña Birlanga $(2000)^{2}$ realizan dos estudios sobre este problema. En el primero, se obvian las causas que provocan la mayor parte de los movimientos existentes, debidos en gran parte a la subsidencia que ha sufrido el terreno. En el segundo, la autora no da una solución a los problemas no tratados inicialmente en la restauración del $\mathrm{BIC}^{3}$ por el arquitecto D. Juan María Boix ni por el arquitecto técnico D. Pedro Sáez. También,

SAEZ, Pedro; "Estudio de restauración de la Iglesia de las Stas. Justa y Rufina, Orihuela" (proyecto fin de Máster, inédito), ejemplar depositado en la Universidad de Alicante, Alicante,1998, pp.47-56.

BIRLANGA, Begoña; Seguimiento de las obras de restauración de la Iglesia de las Stas. Justa y Rufina" (proyecto fin de Carrera, inédito), ejemplar depositado en la Universidad de Alicante, Alicante, 2000, pp. 122-130.

ALVAREZ DE BUERGO, Mónica; GONZÁLEZ, Teresa, Restauración de edificios monumentales, Ministerio de Fomento, Madrid, 2001, pp. 42-47. destacamos que en ambos documentos aparecen grafiadas las lesiones en planos de fachadas, pero no el despiece de su sillería. En la planta cenital de dichos trabajos se reflejan algunas grietas, fisuras en las bóvedas y lesiones por filtraciones, sin embargo, cuando se inicia esta investigación, estudiamos que el número de estas lesiones, tanto las referentes a movimientos estructurales como desperfectos generados por el agua de lluvia, sufren un aumento considerable, especialmente en el volumen de la Capilla de la Comunión y en el espacio que conecta ésta con la Sacristía.

En este artículo presentamos nuevas evidencias históricas, constructivas y patrimoniales para una posible intervención coherente y respetuosa con este BIC, por formar parte de la identidad colectiva del municipio de Orihuela. Dado que le dan un valor artístico y social incalculable, consideramos que estos avances merecen una reflexión por la complejidad de convivencia entre las evidencias de las transformaciones arquitectónicas de la iglesia, desde el punto de vista histórico y constructivo.

\section{Un valioso e innovador proyecto de arquitectura convertido en un BIC}

$\mathrm{Al}$ margen de todas las imprecisiones documentales y de la consiguiente necesidad de hipótesis, para explicar la secuencia de construcción de los espacios del primitivo edificio góti$\mathrm{CO}^{4}$, dedicado a las Santas Justa y Rufina, está claro que, como indica D. Juan Torres (1973) la construcción de la iglesia ha de entenderse en relación con estar incrustada en la mezquita más antigua de la ciudad y dentro del recinto amurallado árabe de Orihuela.

Dentro del casco urbano, en la parte que fue coincidente con la ciudad islámica, D. Francisco Franco (1988) ${ }^{6}$ estableció una referencia arqueológica relativa a tres canales de agua que mueren en el río y que nacen en las inmedia-

\footnotetext{
VV. AA, La luz de las imágenes [texto impreso]: Exposición Semblantes de la Vida, Generalitat Valenciana, Orihuela, marzo-diciembre 2003, pp.32.

5 TORRES, Juan, Colección de documentos para la Historia del Reino de Murcia III. Fueros y privilegios de Alfonso X el Sabio al Reino de Murcia, Academia Alfonso X el Sabio, Murcia, 1973, pp.162-63.

$6 \quad$ FRANCO, Francisco, El espacio del agua en la ciudad de Orihuela en época islámica, Ayuntamiento de Benissa, Benissa, 1988, pp.36.
} 
ciones de la antiguas mezquitas de Orihuela. En dicha referencia arqueológica se ubicaron la Catedral, la Iglesia de las Stas. Justa y Rufina, y la Iglesia de Santiago, permitiéndose situar documentalmente la evacuación de las aguas residuales de los baños islámicos de Orihuela, en las inmediaciones a las tres mezquitas. Este hecho, condicionó el posterior asentamiento y la evolución urbana del espacio socio-religioso de la ciudad de Orihuela.

$\mathrm{Al}$ margen de esta consideración y tras la anexión cristiana, la parroquia quedó en la zona nordeste de la ciudad, de tal modo que la composición de su planta de una sola nave, ligeramente girada respecto a su eje longitudinal, sirvió de paso entre la explanada del Monte de San Miguel, a extramuros, y el barrio de Santa Justa, dentro ya de la sólida Vila Murada. No obstante, puntualizamos que, en realidad, la iglesia que conocemos a día de hoy tuvo que ser acabada cronológicamente en el s. XVIII, debido tanto a las condiciones del entorno como a los problemas del subsuelo y el famoso terremoto de mediados de este siglo. Este hecho obligó a reconstruir gran parte de la cabecera, de la bóveda y de la fachada principal. ${ }^{7}$

Según D. Ernesto Gisbert, en 1319, comenzó a edificarse la traza básica de la fábrica de la iglesia con elementos posteriores a la reconquista, considerándose como una iglesia de culto gótico catalán. Por este motivo, originariamente la primitiva ermita se reconstruyó para la cristianización del territorio urbano y para la articulación de la vida ciudadana ${ }^{8}$. Sin embargo, y a pesar de su aspecto de edificio unitario, podemos decir que es una obra colectiva formada por varias partes. En este sentido, la primitiva iglesia se levantó con una nave única, de piedra de gran amplitud y forma rectangular, de influencia catalana ( $\sin$ crucero), cubierta mediante un total de cuatro tramos con bóvedas de crucería, adaptándose a su especial emplazamiento en el interior de la primitiva ermita.

Con independencia de lo dicho, hasta el primer tercio del s. XIV, apenas hay estudios que aclaren más de lo expuesto, al menos en

VV. AA, La luz de las imágenes [texto impreso], Generalitat Valenciana, Orihuela, marzo-diciembre 2003, pp.132.

8 GISBERT, Ernesto, Historia de Orihuela,1901-1903, II Vol., Editorial Orihuela, Orihuela, pp.612; LLOBREGAT, Enrique, Gótico y Renacimiento en tierras alicantinas: Arte religioso, Alicante, 1990, p.59. lo referido a la construcción gótica de la iglesia. Estudios recientes como el de D. Joaquín Bérchez (1983) ${ }^{9}$, han puesto en relieve la huella de un encuadramiento crono cultural sobre la $1^{a}$ ampliación evolutiva de la iglesia a partir de la torre campanario. Según señala el autor, ésta consistió en la construcción de un ábside poligonal de cuatro lienzos con gruesos contrafuertes exteriores, para contrarrestar los empujes generados en la construcción. Dichos contrafuertes, además, se construyeron con acanaladuras para permitir recoger el agua de lluvia y expulsarla a través de las gárgolas dispuestas en sus extremos. Esta solución permitió cambiar la fisonomía original de la iglesia, transformándose su cuerpo principal al quedar dividido en cinco tramos, de bóvedas simples de terceletes y $\operatorname{combados}^{10}$, con un total de nueve claves contando el altar mayor, ornamentadas con pinjantes a modo de rosetas. Por tanto, la iglesia quedó rematada por una cúpula ligeramente apuntada y marcada por una planta poligonal, pasando a convertirse en un edificio religioso de mayor altura.

Respecto a la parte interior del Templo, destacamos que en los laterales de la nave principal podemos ver ventanales, dos a cada lado de ésta, rematados con arco ojival y parteluz. En relación a ejemplos de reelaboración y pervivencia de modos constructivos y compositivos definidos incidimos que, las columnas de estilo renacentista de la nave central contienen pilastras cajeadas con dos molduras, conservando los basamentos sin modificar y teniendo los capiteles figuras huainas historiadas, con un claro eco a las de la Iglesia de Santiago y la ampliación de la Catedral de Murcia.

Desconocemos la fecha exacta de la construcción de la torre campanario en el lado oeste, de extraordinaria arquitectura gótica, aunque los primeros datos históricos sobre ella los aportó D. Gisbert y Ballesteros, en 131911. Posteriormente, en 1446, gracias a la transcripción de D. Agustín Nieto (1984) se matizaron y

9 BÉRCHEZ, Joaquín, Catálogo de Monumentos y Conjuntos de la Comunidad Valenciana, II Vol., Consellería de Cultura, Educació i Ciència de la G. Valenciana, Servei de Patrimonio Arquitectónic, Valencia, 1983, pp.682-683.

10 La traza de dichas bóvedas se aproxima a la superficie esférica de media naranja y en sus claves se puede apreciar los escudos de la Corona de Aragón, las imágenes de las Stas. Justa y Rufina, y el Oriol (símbolo de la ciudad de Orihuela).

${ }^{11}$ BERCHEZ, Joaquín, opus cit., pp.682-683. 
ampliaron las certezas documentales, dando a conocer que la torre de las Stas. Justa y Rufina es una de las dos únicas torres existentes en la Comunidad Valenciana de estas características del gótico, junto a la torre del Miguelete de la Catedral de Valencia ${ }^{12}$. Las similitudes de ambas torres son manifiestas pese a la diferencia de escala, dado que el lenguaje arquitectónico, el empleo de los materiales y su color son los mismos.

En el tercer tercio del s. XIV el edificio original queda inscrito en un rectángulo, realizándose una transformación a los pies de la nave central, prolongándose la nave principal mediante una estructura de sillería de piedra de forma rectangular y ordenada. Esta cuestión es importante porque en $1349^{13}$ permitió la unión de la iglesia con el conjunto de la torre campanario, adosada al lado norte, pasando la torre a ser el elemento más longevo de su construcción.

Observando la geometría de dicha torre diremos que quedó girada con respecto a la de la nave principal resolviéndose mediante cuatro muros de carga de sillería vista, con sillares que van desde los quince hasta los ochenta centímetros de espesor, con una bóveda interior del mismo material y con juntas de poco espesor. Todo ello, para permitir ubicar una escalera de caracol que da acceso a la parte superior de ésta. La parte exterior de la torre se resuelve con tres contrafuertes acanalados y embebidos, acabados en gabletes y ganchos. Advertimos, asimismo, que la torre queda situada sobre un zócalo de piedra y que consta de cuatro cuerpos. El primero de ellos llega a la altura del tejado de la iglesia y queda separado del siguiente por una moldura de piedra. El segundo, llega a la altura del segundo tejado y termina en una moldura semejante a la anterior, que da inicio al siguiente cuerpo de la torre. El tercer cuerpo comprende tanto la terminación en una moldura semejante a la citada en el cuerpo anterior, y que da inicio al último cuerpo de la torre, como el espacio ocupado por el reloj público de la ciudad, que podemos ver desde la Plaza Mayor. Es necesario puntualizar que es uno de los relojes mecánicos más antiguos de toda la península

12 NIETO, Agustín, Orihuela en sus documentos I. La catedral. Parroquias de Stas. Justa y Rufina y Santiago, t. I. Región de Murcia, 1984, pp.245. Ver A.M.O. n. ${ }^{\circ}$ 198, f. $59 \mathrm{v}$ y $15,2 .^{\circ}$ y $39.2^{\circ}$.

13 BERCHEZ, Joaquín, Catálogo de Monumentos, opus cit., pp.678.
Ibérica, data de 1329, y está compuesto por una saetilla que marcaba las horas y un círculo con números dorados ${ }^{14}$. Respecto al cuarto cuerpo, se abren siete arcos de medio punto repartidos en las caras de las torres y, en los huecos, se colocan las campanas ajustados a las necesidades de éstas. Para finalizar, la construcción quedó rematada por balaustradas de piedra tallada y 6 gárgolas en cada una de sus caras.

Por tanto, podemos decir que las primeras fases constructivas de la iglesia se resumen en dos etapas: el s. XIII momento en que se ejecuta el cuerpo de la nave aprovechando material constructivo de la primitiva ermita y, el s. XIV, con el añadido de la cabecera a la torre campanario gótica.

La constatación de una lógica etapa compositiva de las construcciones del $\mathrm{S}$. $\mathrm{XV}^{15} \mathrm{y}$ la existencia de un gótico valenciano tardío, aún vivo y tangible, como el que se daba en la Catedral, en la Iglesia de Santiago y en la Iglesia de las Stas. Justa y Rufina hace pensar que los tiempos de escasez no permitían muchas alegrías constructivas. Desde el punto de vista arquitectónico, en la iglesia se incorporaron dos tramos de capillas laterales entre los contrafuertes, con estilo más bien renacentista, más estrechas, sobre ménsulas-palomillas, unidas por arcos de medio punto a la principal y divididas en seis cuerpos por las pilastras que soportan los arcos apuntados rebajados, embebidos en la propia fábrica y donde sus sillares comparten con los contrafuertes las mismas características materiales.

Estas circunstancias, sirvieron como punto de apoyo (ver p. e. Fig. 1) para el establecimiento de la siguiente secuencia constructiva de inicios del s. XVI, la obra gótica continúa sufriendo modificaciones. Según D. Agustín Nieto (1984) ${ }^{16}$, el primer registro en 1537, hace

14 CECILIA, Mariano, El patrimonio cultural de la ciudad de Orihuela. Un modelo para la gestión integral de los bienes culturales, Universidad de Alicante, 2015, pp. 94-101, http://hdl.handle.net/10045/50358 consultado el 30/03/2017.

15 Es imposible datarlo, puesto que en el s. XV continúa el desconocimiento general de la vida del monumento dada la falta de información en libros de fábrica o registros históricos. En el estado actual de la investigación no se ha podido llegar más allá del nivel de las hipótesis para el dibujo de las fases de la evolución histórica del monumento.

16 NIETO, Agustín, opus cit., pp.223-224. Ver A.M.O. n. 233, f. 232. 


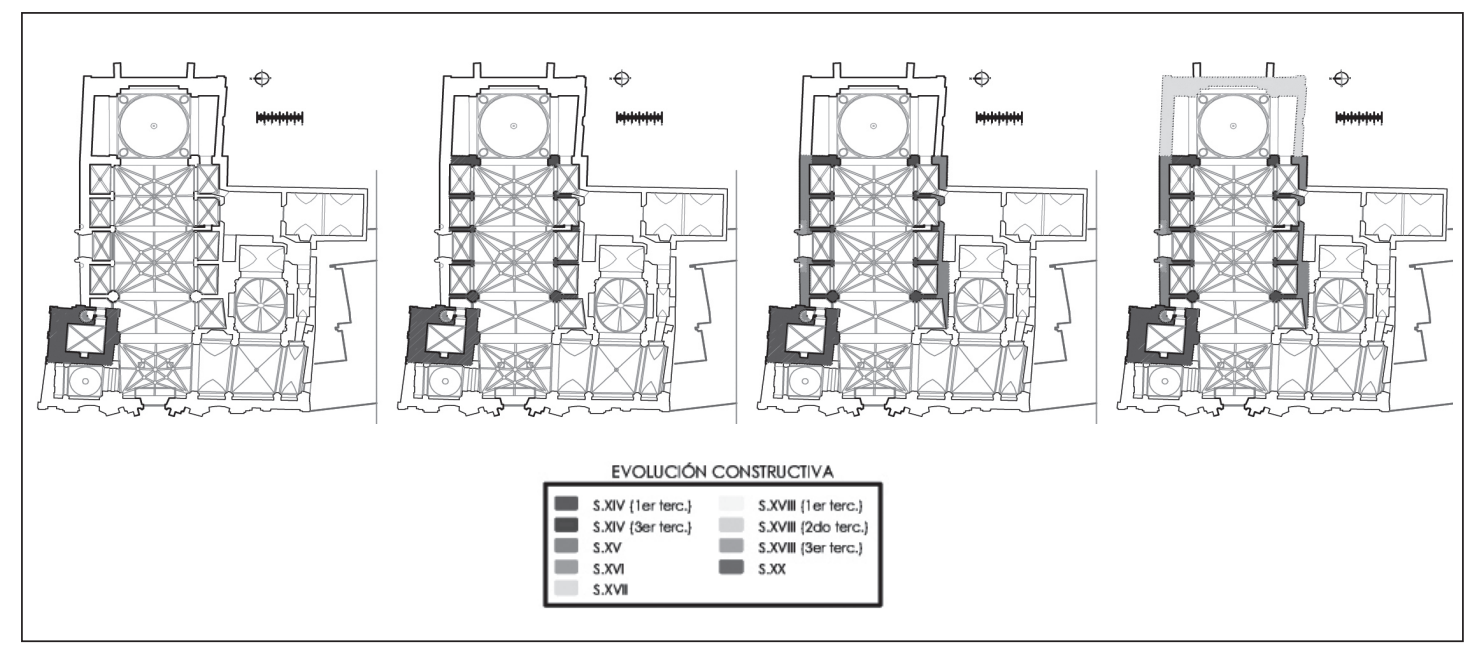

Figura 1. Fases I de la evolución histórica del monumento. Elaboración propia

alusión a las reformas que se llevaron a cabo en la iglesia en 1544, respecto a elevar los muros de la pared del mediodía, a tramontana, en dirección al púlpito nuevo y desde el púlpito hasta el pie derecho del arco que está junto a la Capilla de S. Juan. En ese mismo año, también se remataron las bóvedas de la nave principal, que incluyeron la parte de tramontana sobre la Capilla de San Juan, la Virgen María y la parte central de la Capilla del Corazón; además, de la reconstrucción por el maestro de obras D. Juan Ruiz, del cierre de parte de sus cubiertas con claves, incluidas dos ventanas en la tramontana, capiteles y molduras, semejantes a las anteriores del maestro cantero D. Guillem Comín ${ }^{17}$.

A partir de esta reforma subyace por primera vez la importancia de la perspectiva tanto en la Capilla Mayor de la Nave Central como en la Catedral de Orihuela, rasgo que según D. Pierre Lavedan ${ }^{18}$ era una impronta que marcó la transición del gótico catalán y aragonés hacia los nuevos conceptos renacentistas italianos. Dos años después, en 1546, queda constancia documental, de nuevo según D. Agustín Nieto (1984) ${ }^{19}$ de la intención de dotar a la iglesia de la puerta principal o puerta de las Gradas en el portal de Poniente.

Por tanto, será el s. XVI el que marcará la segunda imagen de la iglesia, tanto en el interior como en el exterior. De hecho, en 1560, el

17 Ídem, pp.225-227. Ver A.M.O. n. ${ }^{\circ}$ 233, f. 269-270.

18 LAVEDAN, Pierre, L Architecture gothique religieuse en Catalogne, Valence et Baléares, opus cit., pp. 65.

19 NIETO, Agustín, opus cit., pp.235-236. Ver A.M.O. n. ${ }^{\circ}$ 235, f. 203-04 y f. 278 v. muro testero este de la iglesia comienza a resentirse y dañarse por el derribo de la Lonja pública de Orihuela, situada en la falda del monte hacia mediodía, frente a la iglesia y coincidiendo con el muro de la ermita dedicada al apóstol San Pablo. Respecto al muro testero decir que se realizó un revestimiento con sillares labrados, con el propósito de enmascarar y ocultar las juntas que existen entre sus piezas como contemporización del muro existente. Este muro se coronó con una cornisa que contenía dos báculos en forma de pirámide, rematados con una esfera y con la función estructural de contrarrestar los posibles empujes de la cúpula, verticalizando las cargas inclinadas que le llegaban. Por ello, en 1560 fue necesario derribar el altar mayor de la iglesia por amenazar ruina, dado que la demolición de la citada lonja le servía de contrafuerte ${ }^{20}$.

A finales del s. XVI, lo que singulariza a la iglesia y le da una transcendencia especial desde el punto de vista de la arquitectura de tradición renacentista es la presencia de un presbiterio, de estilo serliano de concepción manierista desornamentado, en el remate interior de la cabecera del crucero.

El maestro francés D. Agustín Bernardino ${ }^{21}$ reedificó el presbiterio siguiendo los trazados reguladores realizados por D. Jerónimo Quijano en la Iglesia de Santiago ${ }^{22}$, lo cual supuso rigor

20 BERCHEZ, Joaquín, Catálogo de Monumentos, opus cit., pp.679.

${ }_{21}$ VARELA, Santiago, Obra de los arquitectos en Alicante, Editorial, Alicante, 2001, pp.38.

22 VV. AA, Gótico y renacimiento en tierras alicantinas, Caja de Ahorros del Mediterráneo, Alicante, 1990, pp. 21. 
en la aplicación de la geometría. Como novedad, el arquitecto dividió la Capilla del Santísimo en tres tramos y cubrió la correspondiente al presbiterio con una cúpula ligeramente ovalada apuntada, en vez de circular, que arrancaba desde un cubo, con tambor de grandes dimensiones y descansando sobre pechinas ${ }^{23}$, de forma similar a la del Escorial. Desde el punto de vista arquitectónico, por su geometría ovalada, dicho espacio adquiere un protagonismo importante y no sólo sobre la planta. También, aportan singularidad las naves laterales que forman el crucero, dado que delatan formas simples resueltas mediante bóvedas de cañón decoradas con casetones almohadillados, de forma similar a los que aparecen en su cúpula.

A través de D. Agustín Nieto ${ }^{24}$ sabemos que en 1569 , la portada Norte de la Iglesia de las Stas. Justa y Rufina estaba en obras, siendo contratada a los picapedreros D. Juan Ruiz y D. Fernando Vélez, canteros cualificados que solían formar compañía y que ejecutaron también parte de la obra renacentista de la Catedral del Salvador. Debemos aclarar que los citados escultores se ciñeron a la talla de la portada, quedando a la sombra de las trazas dadas por D. Juan Inglés, discípulo de D. Jerónimo Quijano. Claramente se aprecia la huella de la estela de su maestro tanto en lo arquitectónico como en lo escultórico y decorativo y se patentiza en la alta calidad de las labores escultóricas talladas por D. Francisco Ayala. La portada es de decoración compleja y presenta una extrema originalidad. El cuerpo superior está formado por un templete clásico que termina en frontón, con una doble hornacina avenenada entre tres columnas, que sostienen tres ángeles a modo de atlantes con las alas desplegadas. Flaqueando el cuerpo superior, pero esta vez con mayores dimensiones, encontramos dos ángeles que portan las armas de Aragón. De ahí su similitud de estilo con la Portada de la Anunciación de la Catedral del Salvador y de la Catedral de Murcia $^{25}$.

23 NIETO, Agustín, Orihuela en sus documentos I, opus cit., imágenes de la 39-42, pp. 265. De hecho, en la centuria posterior sobre las pechinas de la cúpula se instalarán las pinturas de D. Bartolomé Albert representando las imágenes de San Natal, San Rústico, Santa Bibiana y San Zoilo, todos santos nacidos en Orihuela.

24 Ídem, pp.243. Ver A.H.O, Protocolos de Montiel, año 1.569.

25 VV. AA, La luz de las imágenes [texto impreso]: Exposición, opus cit., pp.44.
Por otro lado, a finales del s. XVI e inicios de la centuria siguiente, se produce uno de los cambios más importantes en la arquitectura del sur de Valencia, dado que se decidió eliminar el ábside poligonal del s. XIV. Esto hizo necesario construir otro ábside, pero esta vez con el nuevo estilo imperante, el Renacimiento, que trajo a la ciudad de Orihuela el citado D. Juan Inglés. El discípulo de D. Jerónimo Quijano introdujo algunas novedades desde el punto de vista formal y constructivo, como el aula capitular $^{26}$. En $1645^{27}$, esta etapa esplendorosa de la arquitectura propició una nueva ampliación en el entorno parroquial de la iglesia, consistiendo tanto en la construcción de la Sacristía, para permitir su acceso desde una de las Capillas laterales, como en el desarrollo de la ornamentación interior de la iglesia. Desgraciadamente esta recuperación se vio truncada por las pestes, de 1648 y $1678^{28}$.

De 1703 a 1706, según las cuentas de fábricas $^{29}$, prosiguen las obras de reparaciones varias. Asimismo, a principios del setecientos, se reanuda la ampliación de la iglesia dado que, se está entrando en un periodo de incipiente prosperidad y abundancia, marcando de nuevo la imagen de la iglesia tanto en el interior como en el exterior, según D. Joaquín Bérchez y D. Francesc Jarque (1993) $)^{30}$. De hecho, el escultor marsellés D. Antonio Dupar realizó en 1727, el monumento eucarístico para la iglesia siguiendo la maestría del escultor D. Nicolás de Busi $^{31}$. Posteriormente, de 1739 a 1742, fue necesario picar las bóvedas de la iglesia y rehacer sus trespoles, a causa de la aparición de grietas en el techo de las mismas, además se decoraron todas las llaves y florones de las bóvedas ${ }^{32}$. En $1744^{33}$, y siguiendo con los cánones del rena-

26 BÉRCHEZ, Joaquín; JARQUE, Francesc, Arquitectura renacentista valenciana, Editorial, Valencia, 1993, pp.78

27 NIETO, Agustín, Orihuela en sus documentos I. opus cit., pp.269. Ver A.M.0. n. ${ }^{\circ}$ 1.464, f.102-04-07-08-16 y f. $116 \mathrm{v}$.

28 CECILIA, Mariano; El patrimonio cultural, opus cit., pp. 555.

29 NIETO, Agustín, Orihuela en sus documentos I. opus cit., pp.267-248 Ver A.M.O. n. ${ }^{\circ}$ 1.546-1548, Cuentas de Fábrica.

30 BÉRCHEZ, Joaquín; JARQUE, Francesc, Arquitectura renacentista, opus cit., pp.152.

31 NIETO, Agustín, Orihuela en sus documentos I. opus cit., pp.295. Ver A.M.O. n. ${ }^{\circ} 1.629$, f.19.

32 Ídem, pp.228-229. Ver A.M.0. n. ${ }^{\circ}$ 1.660, f.31. Cuentas de fábricas, A.M.O. n. ${ }^{\circ}$ 1.669, f.34-38.

33 Ídem, pp.269-270. Ver A.M.0. n. ${ }^{\circ}$ 1.684, f.3. 
cimiento tardío, prosiguieron las obras de ampliación de los espacios de pequeña dimensión de la planta de la iglesia como la sacristía y la casa del sacristán. Destacamos que ambas dependencias fueron diseñadas por el maestro Mayor de la Catedral de Murcia, D. Jaume Bort, quien consiguió uniformar la iglesia según el gusto barroco del momento. La ejecución de la citada ampliación, según D. Santiago Varela (2001), ${ }^{34}$ fue encargada a D. Tomás Gilabert o al maestros cantero, como D. Carrasco. Destacamos que, la planta central de la sacristía que queda situada perpendicularmente a la iglesia, se resuelve mediante dos Capillas, la de la Sagrada Familia y la de la Virgen de Fátima, ambas cubiertas por bóvedas de medio cañón con lunetos sobre arcos fajones y que descansan directamente sobre el muro ${ }^{35}$. Así, la $2^{\text {a }}$ fase fundamental para la morfología final de la iglesia se dio con esta ampliación ${ }^{36}$.

Incidimos que la construcción de la nueva Sacristía se concluyó en el tiempo brevísimo de un año, demostración palmaria de la eficacia organizativa y edificatoria tanto del arquitecto como del maestro de obra D. Jaume Bort. De hecho, de 1745 a 1747, de nuevo se le confía el proyecto de la Capilla de la Comunión (anterior Capilla de la Virgen de la Salud) ${ }^{37}$. La construcción de esta $3^{\text {a }}$ fase supo cubrir tanto la exigencia de convertir el espacio más próximo de la sacristía como el requerimiento de levantar una Capilla más hacia el oeste. Evidentemente, la capilla fue rematada inferiormente con una galería abierta resuelta con bóvedas de crucería, formando un corredor dispuesto de forma paralela a la nave $\mathrm{y}$, adosada al muro de la Epístola de mayor tamaño y con acceso desde el primer tramo de la iglesia, siguiendo el ejemplo del convento valenciano del Carmen ${ }^{38}$. Es decir, vemos una iglesia resuelta con fábricas de sillería que se aligeran en su parte superior, con arcos de medio punto, originándose alturas con relación (1:2) entre los arcos torales y los

\footnotetext{
34 VARELA, Santiago, opus cit., pp.45.

35 BERCHEZ, Joaquín, Catálogo de Monumentos, opus cit., pp.682.

36 JAÉN, Gaspar; MARTÍNEZ, Andrés; OLIVA, Justo; OLIVER, José Luis; SEMPERE, Armando; CALDUCH, Joan, Guía de Arquitectura de la Provincia de Alicante. Such Serra, S.A. L, Alicante, 1999, pp.224; VARELA, Santiago, Obra de los arquitectos, opus cit., pp.44 y sig.

37 BERCHEZ, Joaquín, Catálogo de Monumentos, opus cit., pp.683.

38 Ídem, pp.442 y sig.
}

formeros $^{39}$. Además, destacamos que la iglesia presenta notables diferencias constructivas respecto a la de santa María de Alicante, en comparación con la jerarquización establecida respecto a las impostas de los arcos formeros y la de los arcos torales en los alzados interiores ${ }^{40}$.

El interior de la Capilla es pavimentado en 1748 por D. Cristóbal Sánchez y D. Jaime Galván. Respecto al exterior de la iglesia diremos que, en $1749^{41}$, se acuerda hacer un nuevo tejado y quitar los trespoles, el cual modifica sustancialmente la estructura precedente, ya que tiene que cubrir elementos de mucha mayor superficie, combinándolos con la nave principal. Con posterioridad, en 1753, se aprueban los planos de planta y perfil realizados por el arquitecto fray Antonio Villanueva para la construcción de la pared de poniente donde se ubicó la fachada de los pies $^{42}$. Este diseño pensado desde el punto de vista funcional y estético fue reconocido por dos arquitectos del momento, D. Miguel Francia y D. Diego Tomás, por el gran conocimiento de las matemáticas (basada en la unión de 3 semicircunferencias) y caracterizada por no obedecer al modelo de la fachada retablo, si bien no quedó del todo acabada. En $1755^{43}$, fue necesario quitar los nuevos tejados sobre la nave y bóvedas de las capillas de la iglesia y, en 1765, volver a poner los trespoles. En definitiva, las reformas de la nave de la parte de poniente, los tejados y la pared del poniente de la iglesia quedaron terminadas en $1768^{44}$. De este modo, los espacios de la sacristía, la Capilla de la Comunión y la fachada de los pies supusieron un verdadero cambio en las relaciones espaciales de la iglesia. El arquitecto logra en un ambicioso proyecto la coexistencia entre: el conjunto gótico de los siglos XIV y las fábricas barrocas valencianas más castizas del XVIII, cuyo tratamiento preferencial, en uno $\mathrm{u}$ otro sentido no había dado pie, hasta la fecha, a propuestas acertadas (ver p. e. Fig. 2).

\footnotetext{
39 JAÉN, Gaspar; MARTÍNEZ, Andrés; OLIVA, Justo; OLIVER, José Luis; SEMPERE, Armando, CALDUCH, Joan, opus cit., pp.224.

40 VARELA, Santiago, Arquitecturas en la provincia de Alicante, Instituto de Estudios Juan Gil-Albert, Alicante, 1986, pp.35.

${ }^{41}$ NIETO, Agustín, opus cit., pp.261. Ver A.M.O. n. ${ }^{\circ}$ 1.691, f.20,23,24 y pp. 230. Ver A.M.0. n. ${ }^{\circ} 1.696$, f.21.

42 BERCHEZ, Joaquín, opus cit., pp.683.

43 NIETO, Agustín, opus cit., pp.230-231. Ver A.M.0. n. 1.706, f. 18

44 Ídem, pp.241 y pp.260 (Ver A.M.0. n. ${ }^{\circ}$ 1.714, f.19,25).
} 


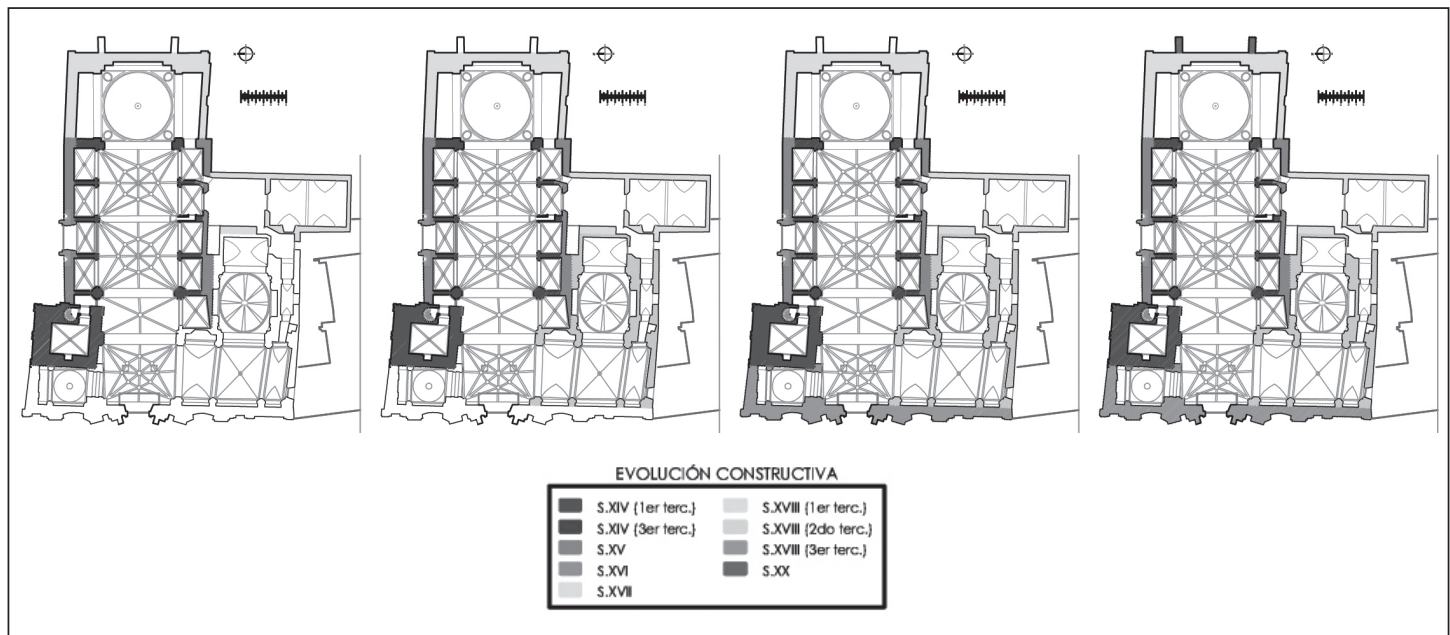

Figura 2. Fase II de la evolución histórica del monumento. Elaboración propia

En el principio del ochocientos, según D. Agustín Nieto (1984), fue necesario continuar realizando sustituciones, como por ejemplo la campana hecha por D. Diego Victoria, o reparaciones en los terrados de las Capillas de la Comunión y Ntra. Sra. de Guadalupe. En la centuria siguiente, en 1902, la iglesia debido al estado ruinoso de la iglesia fue necesario celebrar la función de la Reconquista de la ciudad en la Iglesia de S. Agustín ${ }^{45}$. Un año después, se produjo la sustitución de las antiguas bóvedas de crucería de piedra de la nave principal por otras falseadas de escayola armadas con cañas, además de continuar con los trabajos de mantenimiento de los últimos años ${ }^{46}$.

En $1973^{47}$, cuando el arquitecto conservador de la Iglesia de las Stas. Justa y Rufina D. Alejandro Ferrant Vázquez estaba realizando una intervención en las cubiertas de la Catedral de Orihuela, tuvo que intervenir urgentemente en la cubierta de la nave central.

Tras una entrevista realizada por los autores del artículo al arquitecto D. Santiago Varela nos confirma que, en 1981, realizó una intervención en el muro testero de la iglesia que consistió en la ejecución de dos contrafuertes de hormigón armado, para evitar tanto el desplome que persistía del mismo como sus correspondientes deformaciones. En los años sucesivos el

45 Ídem, pp.232-233. Ver A.M.O. n. ${ }^{\circ}$ 1.792-1.797-1799. Capitular1902-03, f. 17.

46 VARELA, Santiago, Arquitecturas en la provincia, opus cit., pp.34.

47 FERRANT, Alejandro, Biblioteca Valenciana Nicolau Primitiu. Archivo Alejandro Ferrant Vázquez. AAFV 377 (7-3-1965-29-9-1973), pp.19 arquitecto llevó a cabo pequeñas intervenciones para reparar la cubierta y el remate superior de la torre campanario y, además, puntualizó que sustituyo la esfera del reloj por una nueva.

En 1998, la Dirección General de Patrimonio Artístico y la Consellería de Cultura, Educación y Ciencia realizó un encargo al Laboratorio de ensayos del C.O.A.A.T de Alicante para saber el nivel de afección de la humedad en los muros principales de la iglesia. En 1999, la empresa SEG, S.A, por petición de la empresa constructora COMSA S.A, realizó un estudio geotécnico para obtener información del nivel freático existente en el terreno donde se ubica la iglesia ${ }^{48}$.

Un año después, a través de la fundación de la luz de las imágenes se contrata al arquitecto D. Juan María Boix para realizar el estudio de restauración de la Iglesia de las Stas. Justa y Rufina. Se puede consultar al respecto los proyectos completos de D. Pedro Sáez (1998) ${ }^{49}$ y $\mathrm{D}^{\mathrm{a}}$. Begoña Birlanga (2000) ${ }^{50}$. A continuación, en el 2003, dicha fundación publica un catálogo de la exposición ${ }^{51}$, donde incluye diversos artículos sobre las intervenciones realizadas durante ese año, entre las que se encuentra la de la iglesia objeto del artículo. Posteriormente, de 2008 al 2011, se inician las obras que tenían que haber comenzado en 2002 a raíz de los es-

\footnotetext{
MORALES, Luis Jaime, opus cit., pp. 40-47.

49 SAEZ, Pedro, opus cit.,

50 BIRLANGA, Begoña, opus cit.,

51 VV. AA, La luz de las imágenes [texto impreso]: Exposición Semblantes de la Vida, opus cit., pp. 32-41.
} 
tudios realizados por la fundación de la luz de las imágenes ${ }^{52}$.

Aunque pueda parecer obvio, el conocimiento es garantía para la conservación. Cuánto más se conoce al BIC, se está en mejores condiciones de conservar y se disponen de mejores herramientas para la posible intervención de la iglesia. A lo largo de esta investigación hemos podido constatar cómo a partir del análisis de diferentes transformaciones, ampliaciones e intervenciones que el transcurso del tiempo han configurado la imagen actual de la iglesia, somos capaces de poner en valor no sólo una visión de lo patrimonial entendido desde la perspectiva de lo contemporáneo, sino la complejidad de diferentes épocas históricas, que han ido reconstruyendo y enriqueciendo dicho patrimonio, puesto que al fin y al cabo, estamos hablando de un BIC con una fuerte carga histórica que bien merece su puesta en valor, para su posible restauración, y correspondiente difusión.

\section{Estudio, diagnóstico y análisis de la Iglesia de Santas Justa y Rufina}

El estado de conservación general que presenta la iglesia es bastante heterogéneo, ya que mientras algunas de sus zonas no se encuentran alteradas o sufren lesiones de baja importancia otras si aparecen gravemente afectadas. El elemento más dañado es la cúpula ovalada en la Capilla de la Comunión. Tras realizar tanto un estudio pormenorizado de la morfología y desarrollo de las grietas y las fisuras existentes en la Capilla de la Comunión y en los elementos más próximos a su entorno y tras haber analizado los datos extraídos del artículo sobre la subsidencia del terreno de Roberto Tomás et al., podemos relacionar de forma directa las deformaciones existentes en esta zona con el efecto definido en el artículo ${ }^{53}$. Este descenso del te-

52 Información.es, "Las obras de reforma de la iglesia de Santas Justa y Rufina arrancarán en enero”, Diario información, 2008, http://www.diarioinformacion.com/ vega-baja/2008/09/29/obras-reforma-iglesia-santas-justa-rufina-arrancaran-enero/802427.html e Información.es, "Santa Justa amenaza ruina", Diario información, 2011, http://www.diarioinformacion. com/vega-baja/2011/12/23/santa-justa-amenaza-ruina/1204866.html

53 TOMÁS, Roberto., HERRERA, Gerardo., LOPEZ., Juan. Manuel. VICENTE, Fernando; CUENCA, Artemio; MALLORQUÍ, Jordi Joan, Study of the land subsidence in rreno, sumado al conjunto de cargas que recibe la pilastra más próxima al noroeste, consideramos que son las causas que han producido el giro de esta parte de la construcción. Es más, dan como resultado la grieta que se aprecia hoy en día, cuyo desarrollo se relaciona al efecto de charnela, siendo el eje de giro la citada pilastra.

En la intervención del año 2002 se realiza un refuerzo de la cimentación mediante micro-pilotes, en algunos tramos perimetrales (ver p. e. la Fig. 5). Cabe decir que otras zonas no presentan el mismo nivel de afectación estructural. Esta casuística hace temer un posible hundimiento por deformaciones y por ello consideramos requiere de una intervención de urgencia. ${ }^{54}$ Nuestra labor en este artículo aporta, a lo ya expuesto, una visión clara de las lesiones provocadas en el edificio. (ver p. e. Fig.3).

El análisis formal efectuado por quienes nos han precedido como D. Salvador Ivorra et al., (2003) ${ }^{55}$, D. Roberto Tomás et al., (2010) y D. Antonio Rodríguez, (2010) ${ }^{56}$; nos llevó a considerar la subsidencia del terreno como uno de los principales problemas que afectan a la estructura de la iglesia (ver p. e. Fig. 4). Gracias a estas investigaciones hemos podido realizar un análisis comparativo entre las distintas deformaciones medidas en el terreno y las lesiones existentes en el monumento, pudiendo así determinar de forma científica el origen de las

Orihuela City (SE Spain) using PSI data: Distribution, evolution and correlation with conditioning and triggering factors”, Engineering Geology, revista electrónica Elservie, 115 (1-2), 2010, pp. 105-121.

54 El método por excelencia de representación del estudio diagnóstico ha sido y sigue siendo el dibujo de arquitectura, caracterizado por la definición del grafiado de las lesiones provocadas en el edificio, de ahí que decidimos trasladar los niveles de fisuración o agrietamiento a los planos de planta, alzados y secciones, aplicando diferentes intensidades en el trazo y el color (para registrar grietas, alteraciones superficiales en los pétreos, coloraciones, microorganismos, suciedad, etc.), pudiendo valorar un diagnóstico patológico integrado y coherente de la iglesia. Incluimos simbología específica que permite referenciar los movimientos para facilitar su lectura, caso de giros y sentido de avance de desplazamientos.

55 RODRÍGUEZ, Antonio, "Proyecto de recalce de la cimentación con micropilotes de la Iglesia de las Stas. Justa y Rufina de Orihuela" (proyecto fin de Máster inédito), ejemplar depositado en la Universidad de Alicante, 2010.

56 IVORRA, Salvador; PALLARÉS, Francisco, ADAM, José María; TOMÁS, Roberto, "An evaluation of the incidence of soil subsidence on dynamic behavior of a Gothic bell tower", Engineering Structures, 32 (8), 2010, pp. 2.318-2.325. 


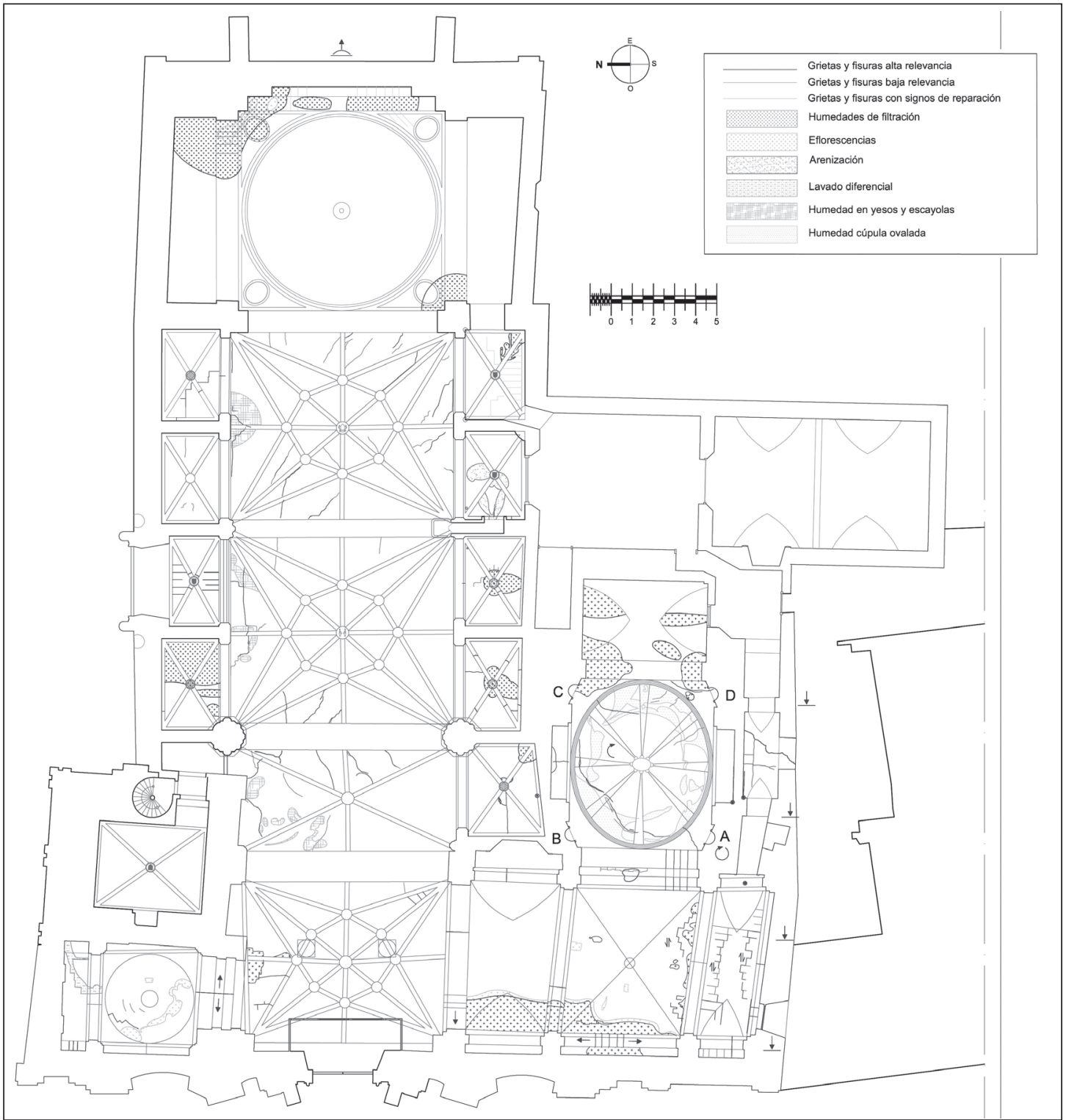

Figura 3. Planta proyección cenital de lesiones terreno. Elaboración propia

grietas y deformaciones de la estructura, junto con el comportamiento de la misma.

Otra información crucial que nos permitió el análisis y las posteriores conclusiones fue la que aportó el estudio geotécnico y el plan de ejecución de los micro-pilotes perimetrales. En la Fig. 5 se aprecian las 3 fases planeadas, 2 de ellas ejecutadas.

Tras el análisis de la subsidencia del terreno consideramos que la solución realizada con la técnica de micro-pilotaje en el proceso de ejecución por fases no fue acertada, dado que facilitó la aparición de asientos diferenciales. Así mismo, para garantizar la estabilidad de la estructura de la iglesia, se debería haber actua- do en la totalidad de elementos de cimentación, muros y pilastras, ya que la subsidencia afecta a todo el terreno. No obstante, somos conscientes de que la zona más próxima al cauce del rio es aquella que está más afectada. (ver p. e. las Fig. 3 y Fig.4).

Respecto al exterior de la iglesia, los movimientos vivos han afectado a parte de las fábricas, apareciendo en estas grietas y fisuras, las cuales no se consideran de gravedad, ya que no comprometen la estabilidad de la construcción. Empero, los mayores problemas que detectamos en los elementos exteriores se relacionan directamente con la alteración y degradación de gran parte de los elementos ornamentales 


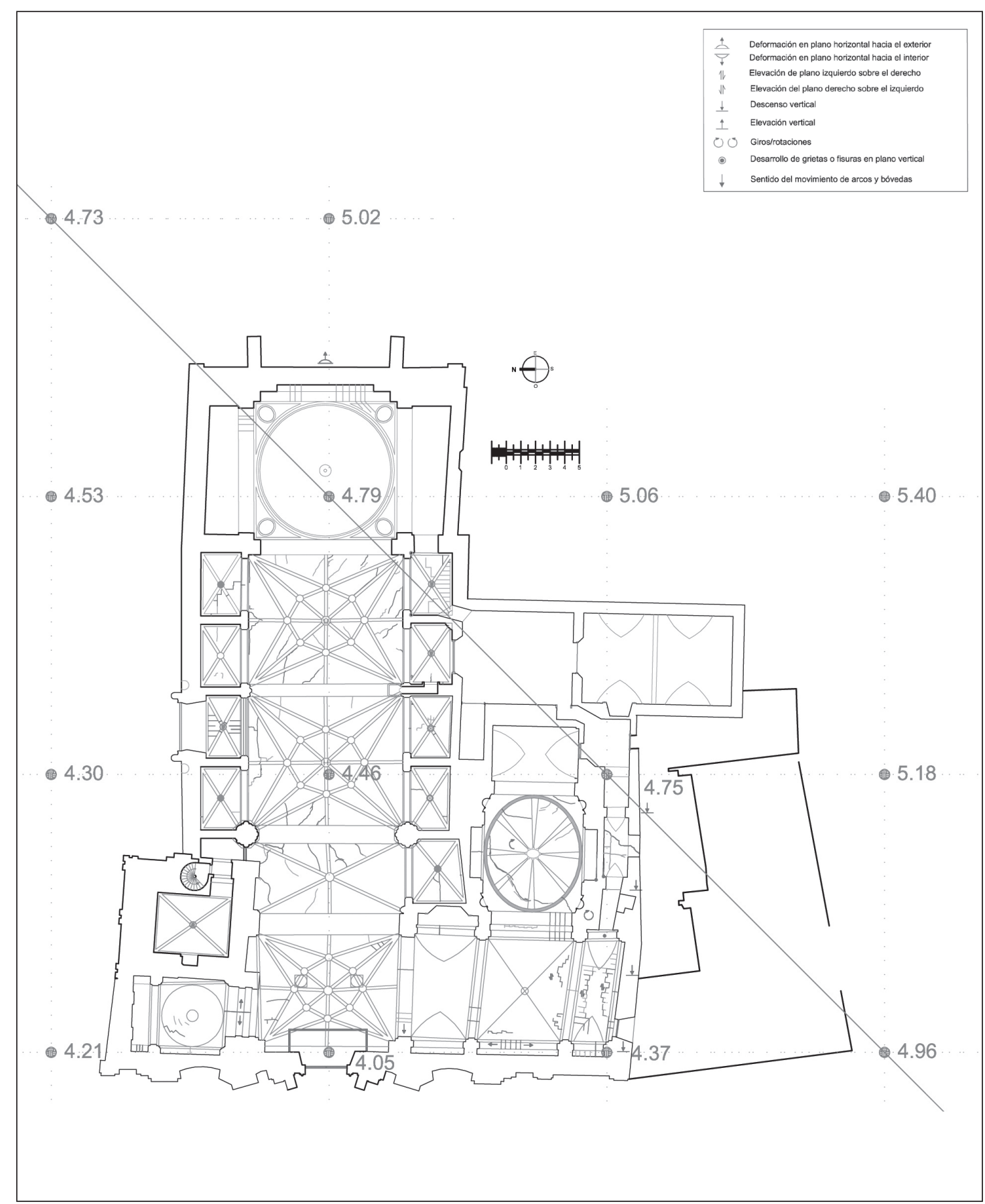

Figura 4. Planta cenital de lesiones por movimientos y medición deformaciones a causa de la subsidencia. Elaboración propia

y escultóricos. Asimismo, una visión del conjunto de la iglesia nos permite clarificar que también aparecen daños graves en la Portada del Evangelio y en la Portada de la Comunión de las Gradas (ver p. e. Fig. 6 y 7).

En la Fig.6 existen superficies con importantes pérdidas de material, especialmente en las hornacinas laterales y en los relieves de los tímpanos del arco que cubre la entrada. Ade- más, aparecen costras de sulfín en los voladizos que separan los cuerpos del conjunto. Como alteración generalizada verificamos numerosas zonas con lavados diferenciales y pátinas de suciedad.

En la Fig.7 las lesiones existentes aumentan en número y gravedad, siendo las más preocupantes las roturas que presentan los voladizos que cubren los frisos en el cuerpo lateral de- 


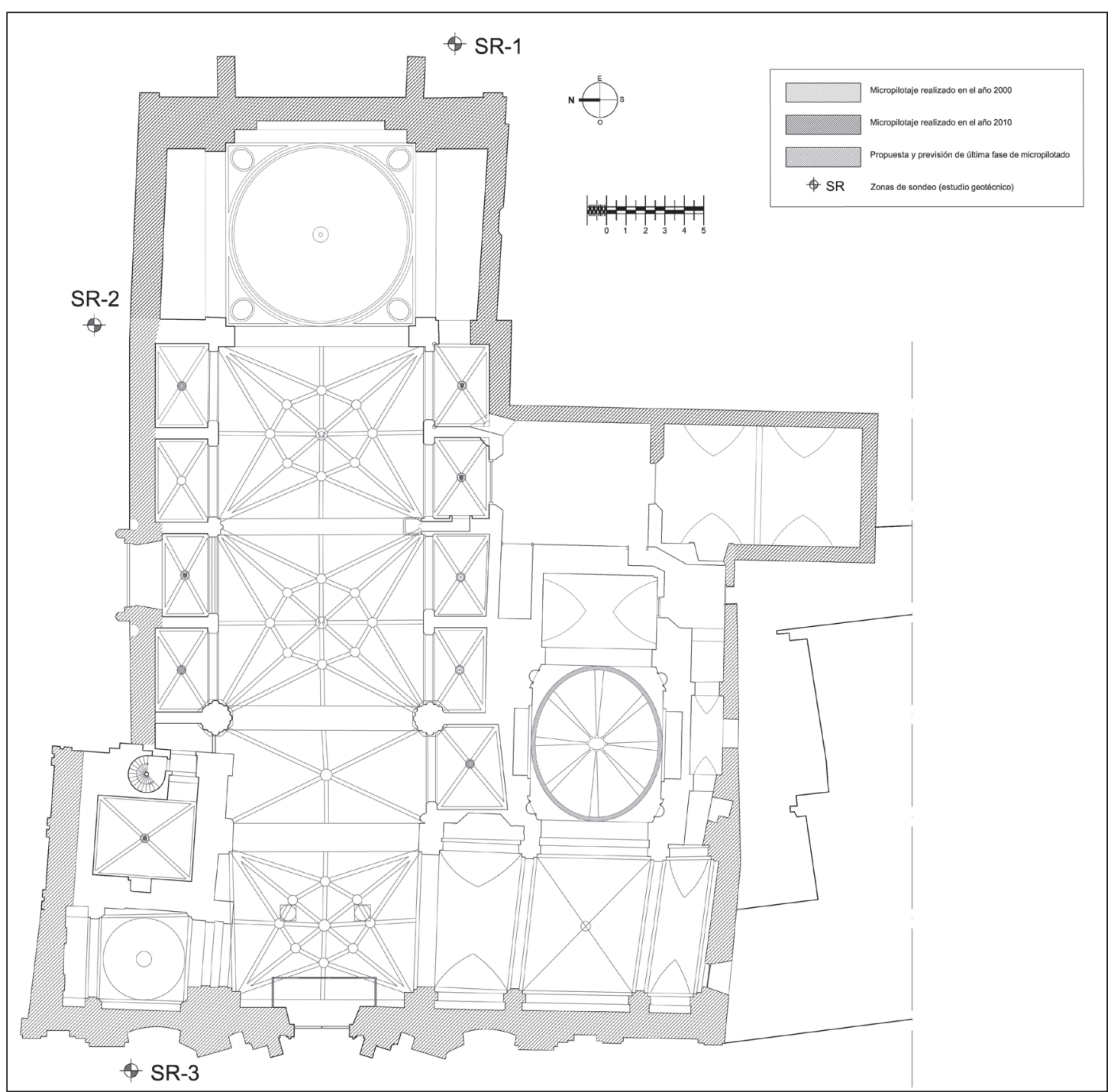

Figura 5. Planta fases de ejecución de micropilotes perimetrales. Elaboración propia

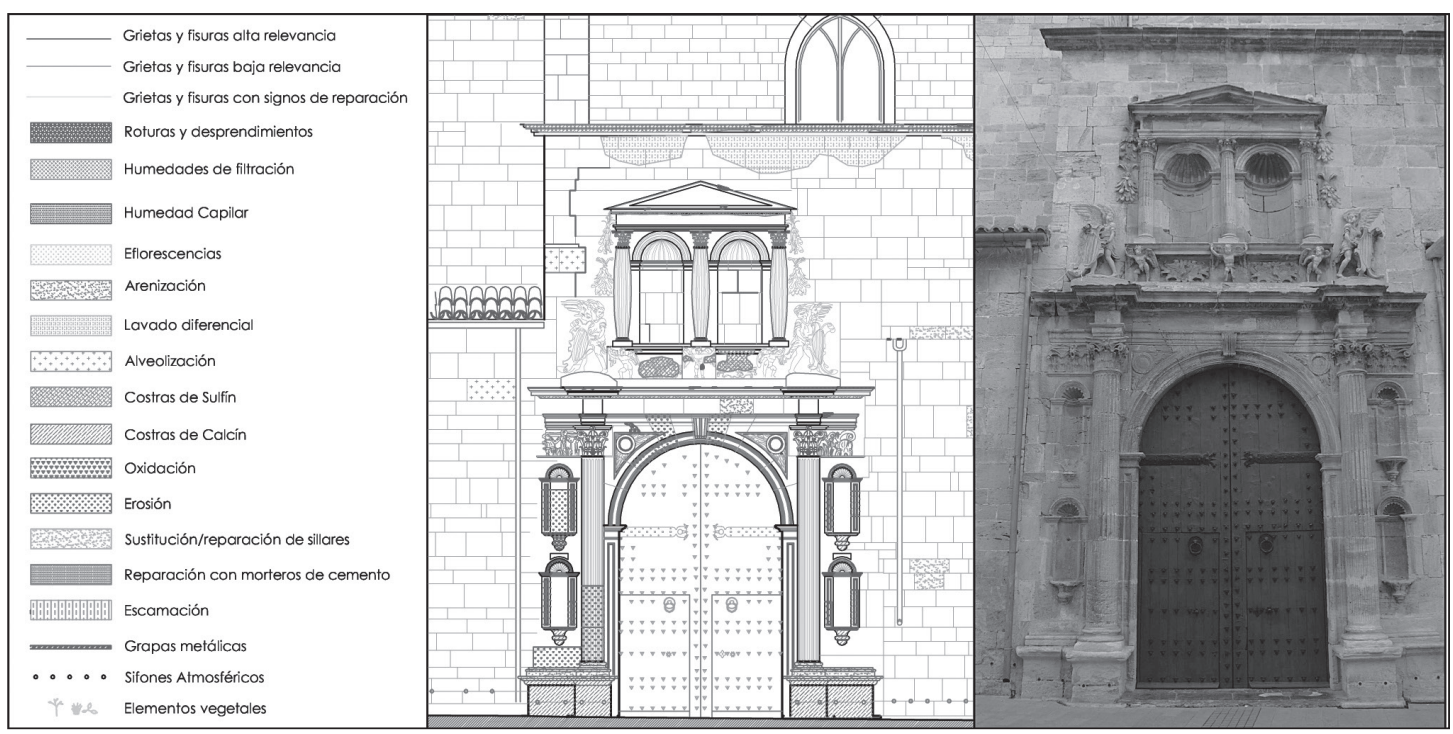

Figura 6. Alzado Norte con lesiones en Portada del Evangelio. Elaboración propia 
recho por estar pérdidas y ser irremplazables. Asimismo, observamos numerosas grietas que se deslizan generalmente con un desarrollo vertical y siguiendo el despiece de los sillares, no presentando un riesgo inminente, pero dada su localización, la causa de las mismas está directamente relacionada con los empujes producidos por las bóvedas de la Capilla de la Comunión. Si sumamos los efectos de dichos empujes laterales y el descenso del terreno por la subsidencia, tenemos como resultado una serie de movimientos y, por ende, desconfiguraciones de las fábricas. Las costras, tanto de calcín como de sulfín, también tienen un desarrollo importante, poniendo en riesgo la talla de los elementos pétreos, especialmente en los frisos.

Sin abandonar esta portada, otra de las lesiones más características que existen es la de la escamación o descamación de la piedra. En este caso, se trata de una pérdida de material en forma de escamas de pocos milímetros de espesor que no compromete la estabilidad del conjunto, pero si facilita la alteración de forma exponencial de la superficie de los sillares, aumentando su superficie de contacto. Cuestión que puede inducir a la aparición de nuevas lesiones de mayor gravedad (alveolizaciones, aparición de costras o microorganismos, etc.). Por otro lado, a pesar de que la putrefacción $\mathrm{u}$ oxidación de la piedra no es una lesión que comprometa la seguridad de la misma, se considera una patología que, además de ser particular, afecta a la estética de la iglesia y se localiza de forma generalizada en las piezas del basamento de la portada principal. Todo ello, es debido tanto a la humedad del terreno existente como a las numeras inundaciones que ha sufrido Orihuela a lo largo de su vida (Cronología de riadas de la Cuenca del Segura, Confederación Hidrográfica del Segura). Además, la absorción de agua de estas piezas de forma intersticial, ha sido la causante de la reacción de la misma con los minerales de hierro que forman parte de la composición mineralógica del material, dando como resultado la tinción característica que puede apreciarse en la actualidad.

Centrando ahora la atención en la torre campanario, consideramos que gran parte de las gárgolas existentes presentan cierto estado de alteración y pérdida de anclaje a las fábricas. A su vez, las decoraciones mediante gabletes $\mathrm{y}$ frondas en el cuerpo superior que acoge las campanas, se encuentran en un estado bastante alterado, afectados tanto por la erosión, por efecto del agua de lluvia y el viento, como por alveolizaciones. También, podemos ver pátinas formadas por microorganismos en aquellas zonas protegidas de la incidencia del sol y en las que el agua queda retenida, dándose tanto en el cuerpo superior que aloja las campanas como en el remate superior de madera que sustenta la de mayor tamaño. Además, observamos cierta falta de mantenimiento y limpieza en los mismos. Respecto a bóveda que cubre este espacio decir que presenta desperfectos por filtraciones de agua de la cubierta plana superior. También, algunos elementos de madera existentes en el remate de la escalera de caracol y en la estructura que conforma la techumbre de la campana superior muestran, en algunas de sus zonas, síntomas de pudrición comprometiendo por tanto la seguridad de los elementos. En la Fig. 8 podemos observar el estado general de las cubiertas, dado que es otro de los aspectos sobre los que hacemos un estudio pormenorizado tratando de encontrar desperfectos y lesiones que faciliten la entrada de agua en la iglesia.

En la Fig. 8 existen numerosos contrapendientes (marcadas con una $\mathrm{C}$ en plano) y puntos de cubierta donde la pendiente es insuficiente o negativa, favoreciendo la acumulación del agua de lluvia. También, localizamos superficies alteradas en zonas alrededor de la cúpula ovalada de la Capilla de la Comunión que han sido tratadas con pinturas impermeables del tipo bituminoso. Finalmente es importante considerar que las entradas de agua más directas las localizamos en la cubierta de las bóvedas de crucería construidas en el acceso de la Portada de las Gradas.

\section{Conclusiones}

El estudio de la iglesia nos sitúa ante una serie de planteamientos interesantes de cara a establecer evidencias constructivas para la posible intervención de este BIC. En primer lugar, el conjunto patrimonial de la iglesia posee un valor artístico e histórico incalculable, testigo del paso de varios siglos de la sociedad de oriolanos que habitaron su territorio, formando parte de su identidad colectiva. El otro aspecto relevante es el notable enriquecimiento que supone el análisis que singulariza y aporta una trascendencia especial a resolver una restauración coherente y respetuosa de este BIC. Para ello, hemos realizado un estudio que recopila 


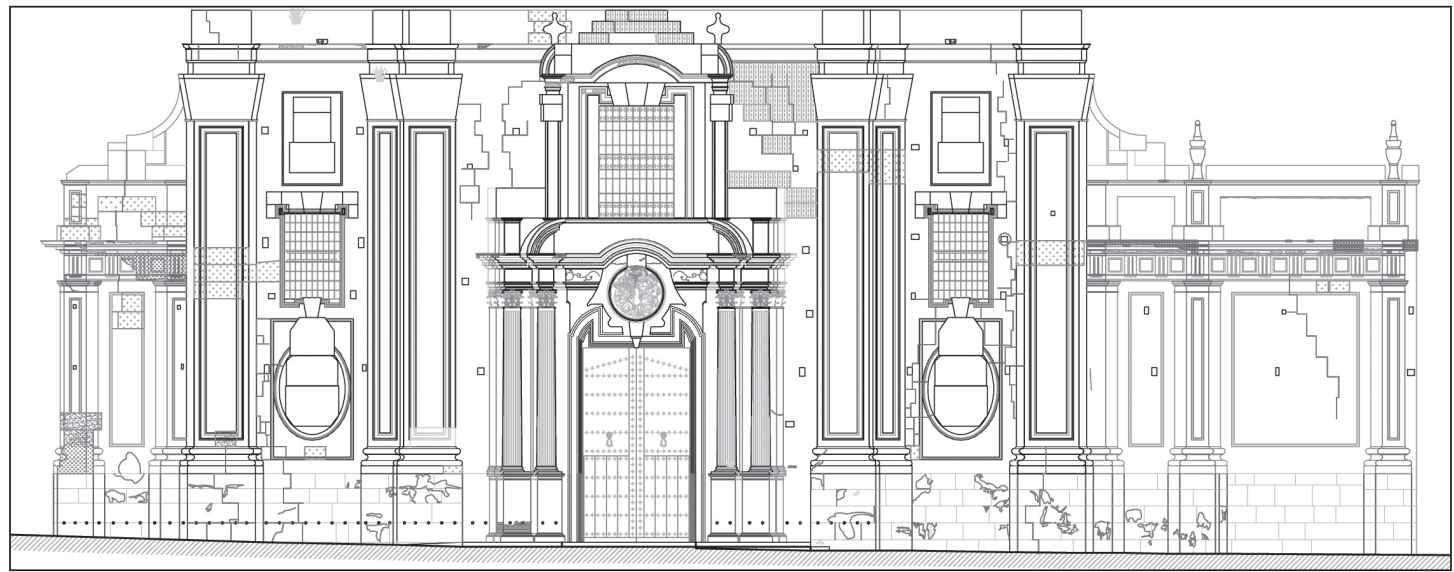

Figura 7. Alzado Oeste con lesiones en Portada de las Gradas. Elaboración propia

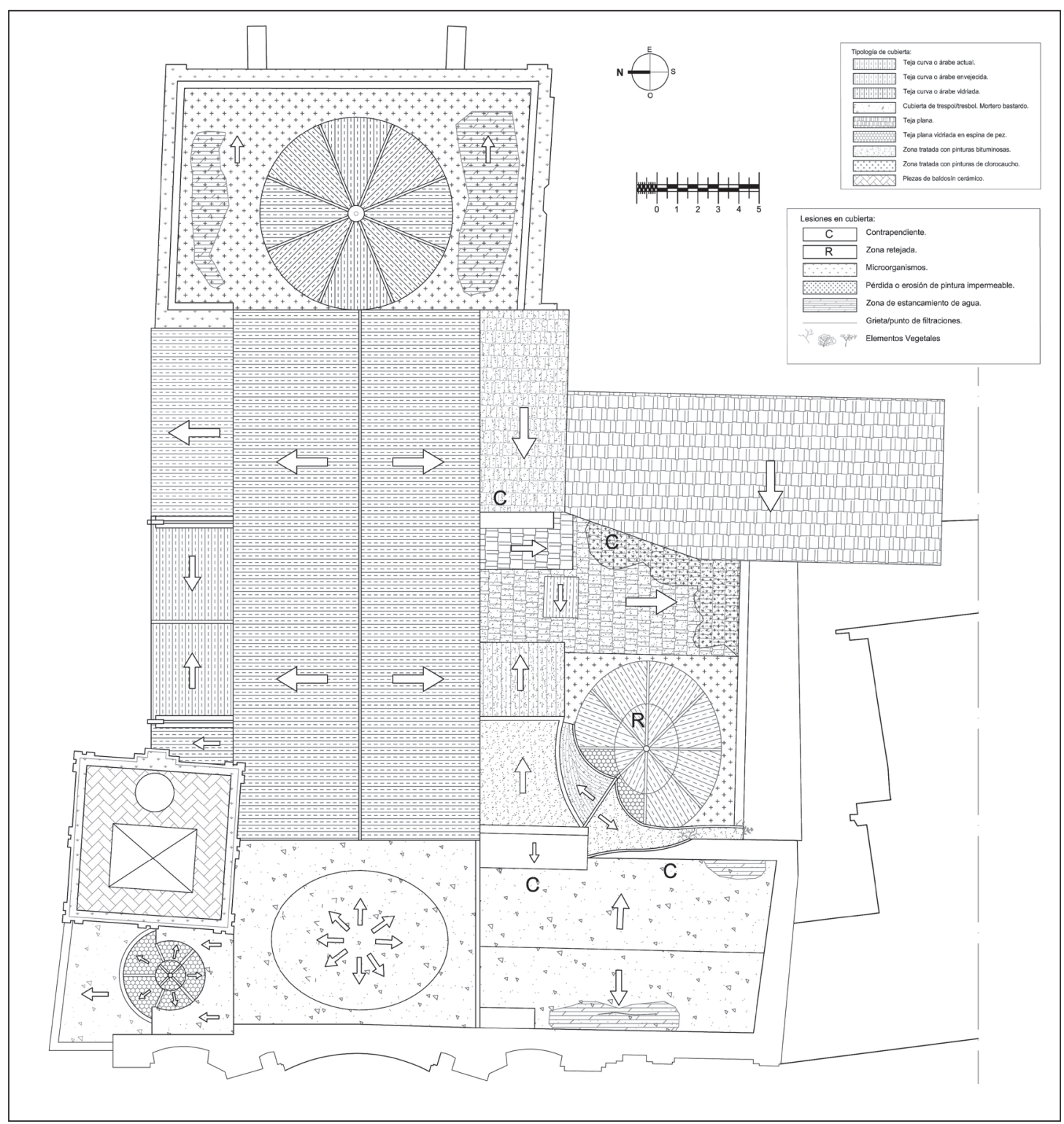

Figura 8. Planta de estado actual de cubiertas. Elaboración propia.

Silvia Spairani Berrio, Yolanda Spairani Berrio, Miguel Louis Cereceda,

LuIS JAIME Morales GisBert
(LIÑO 24. Revista Anual de Historia del Arte. 2018) 
toda la información histórica y descripción de su estado actual permitiéndose acometer, en un fututo, las intervenciones necesarias que garanticen la conservación de un monumento con características únicas en la arquitectura histórica valenciana. Dicho estudio contiene un riguroso levantamiento gráfico que permite documentarlo, conocer su estado actual y en qué estado se conserva, para posteriormente poder valorar la actuación más adecuada en cada lesión (mediante la representación en plantas, alzados y secciones del cuadro figurativo del elemento a restaurar) y sobre todo, darlo a conocer poniéndolo en valor tanto su identidad histórica y cultural como concienciando para conservarlo como la herencia que, material y moralmente, nos han legado nuestros antepasados y que tenemos el deber de mantener para la posteridad, adoptando criterios para que las obras de restauración sean lo menos lesivas para el edificio existente.

Por tanto, debemos fundamentar la intervención en un riguroso proceso de actuación, basado ante todo en el empleo de materiales tradicionales sostenibles, semejantes y compatibles con los elementos de fábrica, con la mayor reversibilidad posible. Con este fin, proponemos en el artículo el análisis histórico, arquitectónico y constructivo de la iglesia de las Stas. Justa y Rufina en Orihuela, que junto a la exposición con planos del estado actual del edificio aportan unas directrices claras y fiables que garantizan la posibilidad de realizar una restauración coherente y respetuosa con el monumento y garantice, en la medida de lo posible, su supervivencia, su puesta en valor y su accesibilidad a lo largo del paso del tiempo.

Acometiendo de forma principal el problema de la subsidencia, dado que es el que puede poner en peligro la estabilidad estructural del monumento, consideramos que debe producirse una intervención global que garantice la seguridad de las fábricas ante las deformaciones de descenso del terreno. Al tratarse de un fenómeno de desarrollo poco controlable y cuya afección a la iglesia no es homogénea, creemos que la intervención debe plantearse asegurando que los elementos resistentes no sufran deformación alguna. Además, en caso que dicha deformación se produzca, sea mínima y conjunta, evitando así asientos diferenciales y variaciones de las líneas de empuje de arcos y bóvedas, ya que estos son los elementos más críticos a la hora de que se produzcan derrumbes. Dado que ya existen 2 fases de micro-pilotaje perimetral realizado (ver p. e. Fig. 5), creemos conveniente continuar con esta solución para evitar posibles incompatibilidades de funcionamiento con otros sistemas constructivos. Para ello, recomendamos completar el estudio geotécnico existente y finalizar el anillo exterior de micro-pilotaje, consiguiendo una correcta unión con los anteriores. Con ello, conseguiríamos una barrera bastante estanca y que, a su vez, permitiera independizar el movimiento del terreno de los alrededores respecto al del inmediatamente inferior a la cimentación de los muros exteriores. Para conseguir un funcionamiento óptimo de esta solución se debería actuar de forma análoga en los elementos de cimentación interiores, perímetros de contrafuertes, pilastras, etc. De esta forma tendríamos estabilizado el conjunto, evitándose que los pavimentos sufrieran deformaciones diferenciales respecto a los elementos resistentes. Es más, deberíamos ejecutar una serie de intervenciones que garantizasen la estabilidad superficial de las capas que lo sostienen. Para conseguir esta estabilidad existen en la actualidad diversos sistemas constructivos que permiten su correcto funcionamiento, desde forjados inferiores debidamente analizados y diseñados a tal efecto, hasta la inyección de resinas estabilizadoras del terreno.

En cualquier caso, debido a la categoría histórica de la construcción, antes de acometer cualquier trabajo en el terreno, tanto exterior como interior, deberíamos realizar una completa campaña arqueológica, la cual permita averiguar y asegurar cada uno de los elementos que aparezcan. Analizados los datos históricos recopilados, la solución empleando resinas se puede desestimar, ya que el refuerzo del pavimento mediante un forjado inferior permite un mayor control de diseño y ejecución, garantizando que los elementos arqueológicos encontrados puedan respetarse en su totalidad. Además, una vez estabilizados los elementos de cimentación, deberíamos acometer con urgencia la restauración de la bóveda ovalada en la $\mathrm{Ca}$ pilla de la Comunión, espacio que lleva cerrado al acceso al público en 2010. La intervención en este elemento de la iglesia debería acometer de forma inicial la ejecución de un apeo completo de la cúpula para que, una vez asegurada, pueda procederse a la retirada de los elementos de teja que la cubren e iniciar la inyección de grietas y fisuras junto con el refuerzo necesario del elemento. Una vez se haya devuelto la esta- 
bilidad estructural a la bóveda, procederemos a colocar de nuevo los elementos que conforman su cobertura y a la restauración del espacio interior. En base a lo mencionado anteriormente, los elementos con mayor necesidad de intervención son las Portadas del Evangelio, de las Gradas y los elementos ornamentales de la torre campanario.

\section{Agradecimientos}

A D. Santiago Varela por permitir consultar y utilizar documentos originales relativos al monumento de Santa Justa y Rufina. 